\title{
Effect of Feedingarginine on the Growth Performance, Carcass Traits, Relative Expression of Lipogenic Genes, and Blood Parametersof Arian Broilers
}

-Author(s)
Pirsaraei ZA'
Rahimi A'
Deldar H'
Sayyadi AJ'
Ebrahimi M"
Shahneh AZ"II
Shivazad M"I
Tebianian M'v
I Animal Science Department, Sari Agricultu-
ral Sciences \& Natural Resources University,
Sari, Iran.
" Animal Science Department, University of
Tabriz, Tabriz, Iran.
"II Animal Science Department, University of
Tehran, Karaj, Iran.
Iv Razi Vaccine and Serum Research Institute,
Karaj, Iran.

\section{Mail Address}

Corresponding author e-mail address Zarbakht Ansari Pirsaraei

P.O.Box 578, Animal Science Department, Sari Agricultural Sciences \& Natural Resources University, Khazarabad, Sari, Iran.

Email: zarbakht_ansari@yahoo.com

\section{-Keywords}

Arginine, Arian broiler chickens, Lipogenic gene expression, Performance.

\section{ABSTRACT}

The aim of this study was to investigate the effects of different dietary levels of L-arginine on the growth performance, blood parameters, and lipogenic gene expression of Arian broiler chickens. For this purpose, 168 Arian broiler chicks $(40.33 \pm 1.7 \mathrm{~g})$ were assigned to four treatments with three replicates of14 birds each, according to completely randomized design. The experimental treatments consisted of $100,124,139$, and $154 \%$ dietary arginine levels relative to the published requirements of Arian broilers. On $42 \mathrm{~d}$ of the experiment, blood samples were collected from two birds (six birds per treatment) for blood metabolite measurements. These birds were then euthanized for carcass evaluation and collection of tissue samples. Increasing dietary arginine levels reduced $(p<0.05)$ the gene expression of fatty acid synthase, acetyl-coenzyme A carboxylase, and malic enzyme in the liver and lipoprotein lipase in the abdominal fat tissue, as well as abdominal fat relative weight. Increasing dietary arginine levels significantly increased $(p<0.05)$ body weight, feed efficiency, carcass yield, breast and thigh relative weights, and glucose and HDL (highdensity lipoprotein) blood levels, and reduced cholesterol, triglyceride, and LDL (low-density lipoprotein) blood levels. Since almost similar performance and carcass trait results were obtained both with 124 and $139 \%$ arginine levels, supplying Arian broiler diets with $124 \%$ arginine is suggested.

\section{INTRODUCTION}

Genetic selection of broiler chickens has resulted in the development of excessive body adiposity along with high muscle mass (Collin et al., 2009). However, excessive fat in broilers are not desirable by producers due their lower feed efficiency, neither by consumers due to health concerns (Ebrahimi et al., 2014). Therefore, finding novel means of improving feed efficiency and stimulating muscle growth without increasing carcass fatness is essential.

Some studies reported positive effects of arginine on broiler weight gain, muscle growth, feed efficiency, and meat quality (Fernandes et al., 2009; Jiao et al., 2010; Al-Daraji \& Salih, 2012a; Ebrahimi et al. 2014, 2016). Al-Daraji \& Salih $(2012 a, b)$ observed higher weight gain, body weight, feed intake, and feed conversion ratio, as well as increasing carcass yield and weight, as well as breast and thigh yields in broilers fed diets with $0.02,0.04$, and $0.06 \%$ arginine compared with the diet no arginine addition. Previous studies with broilers also obtained lower abdominal fat and abdominal adipocyte size, and higher breast muscle fat content and meat production by feeding high levels of arginine (Wu et al., 2011; Ebrahimi et al. 2014). 
Pirsaraei ZA, Rahimi A, Deldar H, Sayyadi AJ, Ebrahimi M, Shahneh AZ, Shivazad M, Tebianian M
Effect of Feedingarginine on the Growth Performance, Carcass Traits, Relative Expression of Lipogenic Genes, and Blood Parametersof Arian Broilers
These effects may indicate the mobilization of energy from the adipose tissue to the skeletal muscle (Tan et al., 2011; Ebrahimi et al., 2014). Tan et al. (2011) showed that the supplementation of $1.0 \%$ arginine in pig diets increased the gene expression of fatty acid synthase in the muscle and of hormone sensitive lipase in the adipose tissue, while it decreased gene expression of glucose transporter-4, lipoprotein lipase, and acetyl-coenzyme A carboxylase- $\alpha$ in the adipose tissue. In an attempt to understand the mode of action of arginine on the fat metabolism of poultry, Ebrahimi et al. (2014) reported that, when Ross broiler chickens were fed high arginine levels, the expression of lipogenic genes was upregulated in the muscle (fatty acid synthase and lipoprotein lipase), and down regulated in the adipose tissue (fatty acid synthase and lipoprotein lipase) and liver (acetyl-coenzyme A carboxylase, fatty acid synthase, and malic enzyme). These results suggest that the addition of arginine to broiler diets may be used to reduce carcass fat content. According to Collin et al. (2009), there is an interaction between genotype and responses to the composition of the diet.

Arian is a native broiler strain of Iran and enhancing its production and carcass quality may aid the country's economy. Accordingly, the arginine requirements of this genotype need to be researched aiming at improving its meat production and quality, reducing carcass fatness. Therefore, the objective of this study was to investigate the effects of different dietary L-arginine levels on the expression of lipogenic genes in the liver and adipose tissue, growth performance, carcass traits, and blood metabolites of Arian broiler chickens.

\section{MATERIALS AND METHODS}

\section{Birds and Housing}

This study was conducted at the department of Animal Science, Sari Agricultural and Natural Resources University, Iran. The experimental protocol was approved by the Animal Care Committee of Sari Agricultural and Natural Resources University.

Birds were managed according to the Arian management guide (Corporation Support of Animal Affairs, 1062539). A total of 168 one-day-old Arian broiler chicks were assigned according to completely randomized design to four treatments with three replicates of 14 birds each. The experimental treatments consisted of diets containing 100, 124, 139 , or $154 \%$ of the arginine requirements of Arian broilers (Corporation Support of Animal Affairs, 2008). Before diet formulation, the chemical composition (AOAC, 1984) and the amino acid contents (Andrews \& Baldar, 1985) of all protein-containing ingredients were analyzed. The basal diets were formulated to supply the nutrient requirements of Arian broilers (Corporation Support of Animal Affairs, 2008), except for arginine, during the starter ( 1 to 10$)$, grower ( $d$ 10 to 24), and finisher (d 24 to 42 ) periods. Arginine was added to the experimental diets as L-arginine (Aldrich, W381918) at the expense of sand (Table 1). Feed and water were provided ad libitum.

\section{Live performance and carcass composition}

Feed intake and body weight were measured at the end of starter ( $d$ 10), grower ( $d$ 24), and finisher (d 42) in order to calculate feed efficiency. On day 42, two birds per replicate (six birds per treatment) were selected, individually weighed after four hours of feed fasting, and euthanized. Eviscerated carcass, abdominal fat, breast, and thigh were weighed, and their weights relative to live body weight were calculated.

\section{Blood metabolite analysis}

Blood samples were collected by heart puncture in non heparinized tubes before the birds were euthanized for carcass evaluation and stored at $4^{\circ} \mathrm{C}$ for approximately $5 \mathrm{~h}$. Samples were then centrifuged $(2,500 * \mathrm{~g}$ for $15 \mathrm{~min})$, and the sera separated and storedat $-20^{\circ} \mathrm{C}$ formetabolite analyses. Glucose, cholesterol, triglyceride, high-density lipoprotein $(\mathrm{HDL})$, and low-density lipoprotein (LDL) serum levels were analyzed byenzymatic and colorimetric method using reagents supplied by Sigma Diagnostics (Zist Shimi Co, Iran) by spectrophotometric assays (Ebrahimi et al., 2014).

\section{Tissue sample collection, RNA extraction and Real-time PCR}

Liver and abdominal fat samples were collected from the birds euthanized for carcass evaluation and stored at $-80^{\circ} \mathrm{C}$ for the evaluation of relative gene expression of the lipogenic enzymes fatty acid synthase (FAS), acetyl-coenzyme A carboxylase (ACC), and malic enzyme (MAE) in the liver, and lipoprotein lipase (LPL) in the abdominal fat. The $\beta$-Actin gene was considered as a housekeeping gene, and RNA extraction was performed according to Ebrahimi et al. (2014) using the same materials. All specific primers for real-time PCR reactions (Methabion, Germany) are shown in Table 2. 


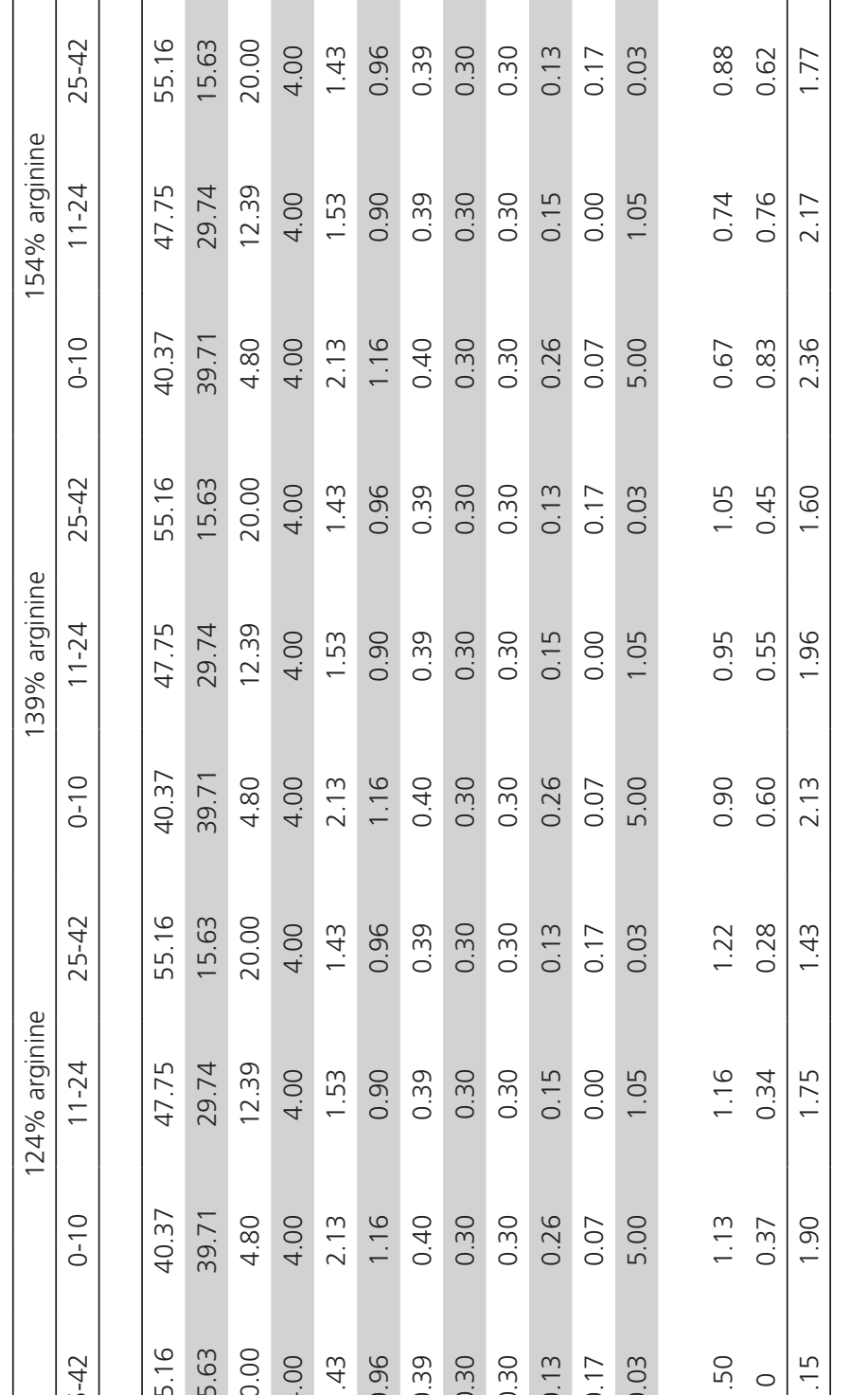

或 
Table 2 - Primer Sequences used for Real-Time PCR.

\begin{tabular}{|c|c|c|c|c|}
\hline Gene $^{1}$ & Primer sequence $\left(5^{\prime}-3^{\prime}\right)$ & Orientation & GenBank accession number & Product size (bp) \\
\hline$\beta$-Actin & $\begin{array}{l}\text { TGCGTGACATCAAGGAGAAG } \\
\text { TGCCAGGGTACATTGTGGTA }\end{array}$ & $\begin{array}{l}\text { Forward } \\
\text { Reverse }\end{array}$ & L08165 & 300 \\
\hline LPL & $\begin{array}{l}\text { CAGTGCAACTTCAACCATACCA } \\
\text { AACCAGCCAGTCCACAACAA }\end{array}$ & $\begin{array}{l}\text { Forward } \\
\text { Reverse }\end{array}$ & NM_205282 & 150 \\
\hline $\mathrm{ACC}$ & $\begin{array}{l}\text { CACTTCGAGGCGAAAAACTC } \\
\text { GGAGCAAATCCATGACCACT }\end{array}$ & $\begin{array}{l}\text { Forward } \\
\text { Reverse }\end{array}$ & J03541 & 447 \\
\hline MAE & $\begin{array}{l}\text { ATGAAGAGGGGCTACGAGGT } \\
\text { CCCATTCCATAACAGCCAAG }\end{array}$ & $\begin{array}{l}\text { Forward } \\
\text { Reverse }\end{array}$ & AF408407 & 470 \\
\hline FAS & $\begin{array}{l}\text { GGAGTCAAACTAGTTATCCATGGCC } \\
\text { AAAGGAGATTCCAGCATCGTGCAGC }\end{array}$ & $\begin{array}{l}\text { Forward } \\
\text { Reverse }\end{array}$ & J04485 & 423 \\
\hline
\end{tabular}

'Abbreviations: LPL, lipoprotein lipase; ACC, acetyl-coenzyme A carboxylase; MAE, malic enzyme; FAS, fatty acid synthase.

\section{Statistical analyses}

Data were analyzed by the General Linear Model procedures of SAS (SAS 9.2, SAS Inst. Cary, NC) and based on a completely randomized design. Initial body weight was considered as covariate in all analyses. Means were compared by Duncan's test and the effects were considered significant at $p<0.05$. Results are presented as least square means \pm SEM.

\section{RESULTS AND DISCUSSION}

\section{Expression of lipogenic genes and abdo- minal fat deposition}

Beta-actin gene expression was not influenced by the treatments. Dietary arginine levels significantly decreased $(p<0.01)$ ACC, FAS, and MAE gene expression in the liver. The lowest expression of the mentioned genes was observed in broilers fed 154\% arginine (Table 3). Moreover, LPL gene expression in the abdominal fat significantly decreased $(p<0.01)$ as arginine levels increased, with the lowest expression observed when the diet with 154\% arginine was fed (Table 3). Furthermore, dietary arginine treatments significantly reduced $(p<0.01)$ relative abdominal fat weight, with the lowest weight observed in the birds fed $154 \%$ arginine (Table 4 ).

The results of the present study are consistent with the findings of Ebrahimi et al. (2014), who reported a decrease in the gene expression of FAS and LPL in the abdominal fat, and of ACC, FAS, and MAE in the liver, accompanied by lower abdominal fat deposition, as well as increased gene expression of FAS and LPL in the muscle of broilers fed diets with high arginine levels. Ducks fed10 g L- arginine/kg diet presented low fat deposition and small adipocytes, as well as low activity of the hepatic lipogenic enzymes malic dehydrogenase, glucose-6-phosphate dehydrogenase, and FAS (Wu et al. 2011). Jiao et al. (2010) also reported a linear

Table 3 - Effects of different dietary arginine levels on the expression of fat-metabolic genes in the liver and abdominal fat tissue of Arian broilers.

\begin{tabular}{|c|c|c|c|c|c|c|}
\hline Variable $^{1,2,3}$ & $100 \%$ arginine & $124 \%$ arginine & $139 \%$ arginine & $154 \%$ arginine & SEM & P-Value \\
\hline FAS - liver & $1.33^{a}$ & $1.03^{b}$ & $0.97^{b}$ & $0.44^{c}$ & 0.06 & $<0.01$ \\
\hline ACC - liver & $2.74^{a}$ & $2.24^{b}$ & $2.13^{b}$ & $0.77^{c}$ & 0.10 & $<0.01$ \\
\hline MAE - liver & $1.04^{\mathrm{a}}$ & $0.76^{\mathrm{ab}}$ & $0.57^{a b}$ & $0.29^{b}$ & 0.14 & 0.03 \\
\hline LPL - abdominal fat & $1.39^{a}$ & $1.00^{b}$ & $0.55^{c}$ & $0.21^{d}$ & 0.05 & $<0.01$ \\
\hline
\end{tabular}

${ }^{1}$ Data are presented as least square means.

${ }^{2}$ mRNA levels were detected using real-time RT-PCR. The comparative Ct value method was also employed for quantifying the expression levels of the target genes relative to $\beta$-actin expression levels.

${ }^{3}$ Abbreviations: FAS, fatty acid synthase; ACC, acetyl-coenzyme A carboxylase; MAE, malic enzyme; LPL, lipoprotein lipase.

$a, b, c, d$ Data with different superscripts within the same row significantly differ $(p<0.05)$.

decrease in the abdominal fat yield of broilers fed increasing dietary levels of arginine $(80,100,120$, and $140 \%$ of the NRC recommendation).

It was demonstrated that the liver is the primary site of fatty acid synthesis in birds, and that fat tissue development relies on the blood availability of triglycerides, which are transported as LDL (Hermier,
1997). The main enzymes involved in fatty acid synthesis in birds' liver are MAE and FAS (Hermier, 1997), while, ACC is responsible for the carboxylation of acetyl-CoA into malonyl-CoA (Tan et al., 2011). Accordingly, low gene expression of these enzymes in the liver reduces fat deposition in the carcass of poultry (Hermier, 1997; Saez et al., 2009; Ebrahimi et al., 2014). As 
Table 4 - Effects of different dietary arginine levels on the growth performance, carcass traits, and blood metabolites of Arian broilers.

\begin{tabular}{|c|c|c|c|c|c|c|}
\hline Variable $^{1}$ & $100 \%$ arginine & $124 \%$ arginine & $139 \%$ arginine & $154 \%$ arginine & SEM & P-Value \\
\hline Body weight (g), (d 10) & $131.17^{b}$ & $150.33^{a}$ & $156.00^{\mathrm{a}}$ & $156.50^{\mathrm{a}}$ & 5.94 & 0.03 \\
\hline Feed efficiency (d 1-10) & 0.60 & 0.66 & 0.65 & 0.59 & 0.02 & 0.16 \\
\hline Body weight (g), (d 24) & $626.67^{a b}$ & $640.88^{a}$ & $646.83^{a}$ & $595.00^{b}$ & 10.75 & 0.02 \\
\hline Feed efficiency (d 11-24) & $0.55^{b}$ & $0.65^{a}$ & $0.65^{a}$ & $0.57^{\mathrm{ab}}$ & 0.02 & 0.03 \\
\hline Body weight (g), (d 42) & $1836.66^{b}$ & $1958.33^{a}$ & $1966.67^{a}$ & $1811.67^{b}$ & 34.03 & 0.01 \\
\hline Feed efficiency (d 25-42) & $0.52^{c}$ & $0.63^{\mathrm{ab}}$ & $0.64^{a}$ & $0.55^{b c}$ & 0.02 & 0.01 \\
\hline Carcass yield (\%), (d 42) & $57.62^{b}$ & $68.17^{\mathrm{a}}$ & $67.53^{\mathrm{a}}$ & $58.43^{b}$ & 2.40 & 0.01 \\
\hline Relative breast weight (\%), (d 42) & $20.61^{c}$ & 23.29 ab & $23.40^{a}$ & $21.62^{\mathrm{bc}}$ & 0.55 & $<0.01$ \\
\hline Relative thigh weight (\%), (d 42) & $16.14^{c}$ & $18.23^{\mathrm{a}}$ & $18.08^{\mathrm{ab}}$ & $16.39^{\mathrm{bc}}$ & 0.55 & 0.03 \\
\hline Relative abdominal fat tissue weight (\%), (d 42) & $1.78^{a}$ & $1.38^{\mathrm{b}}$ & $1.20^{\mathrm{b}}$ & $1.08^{\mathrm{b}}$ & 0.09 & $<0.01$ \\
\hline \multicolumn{7}{|l|}{ Metabolites } \\
\hline Glucose (mg/dL) & $195.33^{b}$ & $202.16^{\mathrm{ab}}$ & $218.50^{\mathrm{a}}$ & $223.33^{a}$ & 6.86 & 0.04 \\
\hline Cholesterol (mg/dL) & $128.33^{\mathrm{a}}$ & $118.01^{\mathrm{ab}}$ & $112.50^{\mathrm{b}}$ & $109.33^{b}$ & 4.01 & 0.03 \\
\hline Triglyceride (mg/dL) & $109.67^{\mathrm{a}}$ & $103.83^{\mathrm{a}}$ & $82.33^{b}$ & $80.83^{b}$ & 5.91 & $<0.01$ \\
\hline $\mathrm{HDL}^{2}$ (mg/dL) & $61.83^{b}$ & $58.33^{b}$ & $73.50^{\text {a }}$ & $74.50^{\text {a }}$ & 3.44 & 0.01 \\
\hline $\mathrm{LDL}^{3}(\mathrm{mg} / \mathrm{dL})$ & $40.27^{a}$ & $27.33^{b}$ & $23.40^{b}$ & $13.27^{c}$ & 1.75 & $<0.01$ \\
\hline
\end{tabular}

${ }^{1}$ Data are presented as least square means

${ }^{2}$ High-density lipoprotein.

${ }^{3}$ Low-density lipoprotein.

$a, b, c$ Data with different superscripts within the same row significantly differ $(p<0.05)$.

$\mathrm{LPL}$ is the primary enzyme responsible for the uptake of fatty acids by the adipose tissue (Zechner, 1997), a decrease in LPL gene expression in the abdominal fat tissue causes reduced the entry of fatty acids into the adipocytes and adipose tissue growth (Hermier, 1997; Ebrahimi et al., 2014).

Nitric oxide (NO) is synthesized from L-arginine in almost all cells and tissues by different isoforms of NO synthase (Jobgen et al, 2006). Studies have demonstrated the role of NO in stimulating lipolysis and fatty acid oxidation in adipose tissue, and also that feeding L-arginine induced the same results by stimulating NO production (Jobgen et al, 2006; Jobgen, 2007). Moreover, NO affects lipid synthesis in the hepatocytes by decreasing ACC activity (Jobgen, 2007). Therefore, it seems that the reduced expression of lipogenic genes observed in the present study by feeding L-arginine may be mediated by the roles of NO on lipid metabolism.

\section{Growth performance and carcass com- position}

Dietary arginine levels significantly increased $(p<0.05)$ the bodyweight (BW) of 10-, 24-, and 42-d-old broilers, as well as the feed efficiency (FE) measured on days 24 and 42 (Table 4). The highest BW and FE were observed in the broilers fed $139 \%$ and $124 \%$ arginine, while statistically similar BW and FE when the diets with $154 \%$ and $100 \%$ arginine were fed, except for BW on day 10 (Table 4). Furthermore, arginine levels significantly influenced $(p<0.05)$ carcass yield, and breast and thigh relative weights (Table 4). The highest carcass yield and thigh relative weight were obtained with $124 \%$ arginine, while the highest breast relative weight was observed in the $139 \%$ arginine treatment group (Table 4).

These results are in agreement with Ebrahimi et al. (2014), who fed Ross broilers with increasing digestible arginine levels up to $168 \%$ relative to their requirements, and observed improvements in growth performance (higher BW, average daily weight gain, and feed efficiency) and carcass composition (higher breast and thigh weights). Murakami et al. (2012) reported that dietary arginine supplementation increased the live weight and feed conversion ratio of broilers. Emadi et al. (2010) showed that high dietary arginine levels increased the body weight gain and feed intake of Cobb broiler chickens. In another study, the addition of0.04 and $0.06 \%$ arginine to broiler diets increased carcass weight, carcass yield, and breast, thigh, and drumstick yields (Al-Daraji \& Salih, 2012a). Khajali et al. (2013) demonstrated that addition of 15 $\mathrm{g}$ arginine/ $\mathrm{kg}$ diet (120\% of the NRC recommendation) promoted the best broiler performance. Jiao et al. (2010), evaluating increasing dietary arginine levels $(80,100$, and $120 \%$ of the NRC recommendation), reported a linear increase in breast and leg meat yields. Munir et al. (2009) found that adding $2 \%$ arginine to the diet promoted higher broiler body weight. Fernandes et al. (2009), adding increasing 
Pirsaraei ZA, Rahimi A, Deldar H, Sayyadi AJ, Ebrahimi M, Shahneh AZ, Shivazad M, Tebianian M
Effect of Feedingarginine on the Growth Performance, Carcass Traits, Relative Expression of Lipogenic Genes, and Blood Parametersof Arian Broilers digestible arginine levels to a starter diet, observed a linear increase in breast and breast fillet weights, as well as in myofiber diameter. Kidd et al. (2001) fed broilers with $120 \%$ of the NRC arginine and lysine recommendations and did not find any interaction between dietary Lys and Arg; however, when Arg, but not Lys, levels were increased to up $120 \%$ of the NRC recommendations, body weight gain increased. Moreover, Gorman et al. (1997) suggested that high dietary arginine to lysine ratio is required to optimize breast meat yield of broilers reared at thermoneutral temperatures. The different optimal level of arginine to stimulate growth observed in the present study may be attributed to the broiler strain evaluated (Arian), which may have specific requirements, as well as to the different feed formulation and experimental design applied compared with the mentioned studies.

Arginine may enhance broiler growth through several pathways. Arginine stimulates secretion of insulin and of growth hormone to promote growth (Jahanian, 2009; Fernandes et al., 2014). Birds are not able to endogenously synthesize arginine due to the absence of a functional urea cycle, and therefore, arginine is considered an essential amino acid that should be supplied in the feed. It was shown that insufficient dietary arginine directly affects protein synthesis in birds (Fernandes et al., 2009). Part of the effects of arginine may be exerted through the formation of polyamines (putrescine, spermidine, and spermine), which promote growth through their role in the synthesis of DNA, RNA, and proteins, and by improving the uptake of amino acids by the cells (Jahanian, 2009; Khajali \& Widerman, 2010, Basoo et al., 2012). Arginine is also a substrate for the synthesis of nitric oxide (NO) by activating NO synthase in all cell types; NO has multiple roles, including muscle growth and fat reduction, enhancement of the immune system, and regulation of cardio-pulmonary blood flow (Jobgen et al., 2006; Khajali \& Widerman, 2010). Therefore, the favorable effects of arginine on broiler growth performance and carcass traits may be mediated by any of the above-mentioned mechanisms. According to the results of the present study that showed no performance or carcass differences in broilers fed either 124 and $139 \%$ arginine, the supply of $124 \%$ arginine relative to the published requirement of Arian broilers, is recommended.

\section{Blood metabolites}

Dietary arginine levels influenced glucose and HDL serum levels $(p<0.05)$, with the highest levels obtained with 139 and 154\% arginine (Table 4). On the other hand, increasing arginine levels reduced cholesterol, triglyceride, and LDL serum levels $(p<0.05)$. The lowest cholesterol and triglyceride levels were observed in birds fed 139 and $154 \%$ arginine, and the lowest LDL level was obtained with the $154 \%$ arginine treatment (Table 4).

Ebrahimi et al. (2014) did not find any effects of higher dietary arginine levels on glucose serum levels, but observed reduced urea, cholesterol, and triglyceride levels. Emadi et al. $(2010,2011)$ reported that increasing arginine levels in the diet of broiler chickens increased albumin, total protein, and glucose serum levels, and reduced cholesterol and triglyceride levels. On the other hand, Ma et al. (2010) did not find any influence of dietary arginine supplementation on the serum levels of cholesterol, free fatty acids, glucose, urea, LDL, triglycerides or insulin in finishing pigs. Tan et al (2009), adding 1.0\% L-arginine ingrowingfinishing pigs' diet, reported lower triglyceride levels, but no effect on LDL, HDL, glucose, or cholesterol levels. Jobgen (2007) observed reduced glucose and triglyceride serum levels in diet-induced obese rats supplemented with $1.51 \% \mathrm{~L}$-arginine $\mathrm{HCl}$. The addition of $1.0 \% \mathrm{~L}$-arginine in the diet of growing pigs increased glucose serum levels, tended to increase HDL levels, and reduced lipid, urea, VLDL, and triglyceride levels (He et al. 2009).

As the de novo synthesis of fatty acids mainly takes place in the liver of birds, the main transporter of triglycerides is VLDL (Hermier, 1997). The results of the present study showed a reduction in the expression of lipogenic genes in the liver, which resulted in low flow of lipids in the blood (low serum levels of cholesterol, triglyceride, and LDL). In addition, arginine can change lipid metabolism by synthesizing nitric oxide (Jobgen et al., 2006) and increasing thyroid hormone blood concentrations (Ebrahimi et al., 2014), consequently reducing lipid blood concentrations (Jobgen et al., 2006; Hall, 2015). On the other hand, the protein synthesis promoted by arginine through the mentioned mechanisms may explain the high HDL results of the present study. The observed high glucose levels with increasing dietary arginine level maybe attributed to the glycogenic properties of arginine (Foye et al., 2006).

The overall results of this study indicated that supplying 124 and $139 \%$ arginine in the diet of Arian broiler chickens reduced the expression of lipogenic genes in the liver and abdominal fat tissue, and improved the growth performance and the profile of blood metabolites. Since almost similar performance and carcass trait results were obtained both with the 
Pirsaraei ZA, Rahimi A, Deldar H, Sayyadi AJ, Ebrahimi M, Shahneh AZ, Shivazad M, Tebianian M

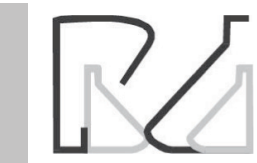

124 and 139\%arginine treatments, supplying Arian broiler diets with $124 \%$ arginine is suggested.

\section{ACKNOWLEDGEMENTS}

The authors thank Iran National Science Foundation (Project No. 9000883), Tehran, Iran and the research council of the Sari Agricultural Sciences and Natural Resources University, Sari, Iran, for supporting this research.

\section{REFERENCES}

Al-Daraji HJ, Salih AM. Effect of dietary L-arginine on carcass traits of broilers. Research Opinions in Animal and Veterinary Sciences 2012a;2:40-44.

Al-Daraji HJ, Salih AM. Effect of dietary L-Arginine on productive performance of broiler chickens. Pakistan Journal of Nutrition 2012b;11:252-257.

Andrews RP, Baldar NA. Amino acid analysis of feed constituents. Science Tools $1985 ; 32: 44-48$.

AOAC - Association of Official Analytical Chemists. Official methods of analysis. $14^{\text {th }}$ ed. Arlington: Association of Official Analytical Chemists; 1984.

Basoo H, Khajali F, Asadi Khoshoui E, Faraji M, Wideman R F. Reevaluation of arginine requirements for broilers exposed to hypobaric condition during the 3-to 6-week period. Journal of Poultry Science 2012;49:303307.

Collin A, Swennen Q, Skiba-Cassy S, Buyse J, Chartrin P, Le BihanDuval $E$, et al. Regulation of fatty acid oxidation in chicken (Gallus gallus):Interactions between genotype and diet composition. Comparative Biochemistry and Physiology Part B: Biochemistry and Molecular Biology 2009;153:171-177.

Corporation Support of Animal Affairs. Arian broiler chicken management guide breeding. Tehran; 2008. p.1-57. [In Persian]

Ebrahimi M, Zare Shahneh A, Shivazad M, Ansari Pirsaraei Z, Ghafari Balesini M. The effects of dietary L-arginine on some parameters of meat quality, intestine histology and immune system of 46 - $d$ old broiler chickens. Journal of Animal Science Researches 2016;26:83-96. [In Persian]

Ebrahimi M, Zare Shahneh A, Shivazad M, Ansari Pirsaraei Z, Tebianian M, Ruiz-Feria CA, et al. The effect of feeding excess arginine on lipogenic gene expression and growth performance in broilers. British Poultry Science 2014;55:81-88.

Emadi M, Jahanshiri F, Kaveh K, Hair-Bejo M, Ideris A, Alimon AR. Nutrition and immunity: the effects of the combination of arginine and tryptophan on growth performance, serum parameters and immune response in broiler chickens challenged with infectious bursal disease vaccine. Avian Pathology 2011;40:63-72.

Emadi M, Kaveh K, Bejo MH, Ideris A, Jahanshiri F, Ivan M, et al. Growth performance and blood parameters as influenced by different levels of dietary arginine in broiler chickens. Journal of Animal Veterinary Advance 2010;9:70-74.

Fernandes JIM, Murakami AE, Gomes de Souza LM, Ospina-Rojas IC, Rossi RM. Effect of arginine supplementation of broiler breeder hens on progeny performance. Canadian Journal of Animal Science 2014;94:313-321.
Effect of Feedingarginine on the Growth

Performance, Carcass Traits, Relative Expression of Lipogenic Genes, and Blood Parametersof Arian

Broilers

Fernandes JIM, Murakami AE, Martins EN, Sakamoto MI, Garcia ERM Effect of arginine on the development of the pectoralis muscle and the diameter and the protein: deoxyribonucleic acid rate of its skeletal myofibers in broilers. Poultry Science 2009;88:1399-1406.

Foye OT, Uni Z, McMurty JP, Freket PR. The effects of nutrient administration, "In ovo feeding" of Arginine and/or $\beta$-hydroxy- $\beta$-methyle butyrate $(\mathrm{HMB})$ on insulin-like growth factors, energy metabolism and growth in turkey poults. International Journal of Poultry Science 2006;5:309317.

Gorman I, Balnave D, Brake J. The effect of altering the dietary arginine to lysine ratio on the breast meat yield of broiler chickens at moderate and high temperatures. Australian Journal of Agricultural Research 1997;48:709-714.

Hall JE. Guyton and Hall textbook of medical physiology e-book. 13thed. Philadelphia: Elsevier Health Sciences; 2015. p.954-957.

He Q, Kong X, Wu G, Ren P, Tang H, Hao F, et al. Metabolomic analysis of the response of growing pigs to dietary L-arginine supplementation. Amino Acids 2009;37:199-208.

Hermier D. Lipoprotein metabolism and fattening in poultry. The Journal of Nutrition 1997;127:805S-808S.

Jahanian R. Immunological responses as affected by dietary protein and arginine concentrations in starting broiler chicks. Poultry Science 2009;88:1818-1824.

Jiao P, Guo Y, Yang X, Long F. Effect of dietary arginine and methionine levels on broiler carcass traits and meat quality. Journal of Animal and Veterinary Advances 2010;9:1546-1551.

Jobgen WS. Dietary l-arginine supplementation reduces fat mass in dietinduced obese rats [dissertation]. Texas (USA): Texas A\&M University; 2007.

Jobgen WS, Fried SK, Fu WJ, Meininger CJ, Wu G. Regulatory role for the arginine-nitric oxide pathway in metabolism of energy substrates. Journal of Nutritional Biochemistry 2006;17:571-588.

Khajali F, Widerman RF. Dietary arginine: metabolic, environmental, immunological and physiological interrelationships. World's Poultry Science 2010;66:751-766.

Khajali1 F, Basoo1 H, Faraji M. Estimation of arginine requirements for male broilers grown at high altitude from one to twenty-one days of age. Journal of Agricultural Science and Technology 2013;15:911-917

Kidd MT, Peebles ED, Whitmarsh SK, Yeatman JB, Wideman RF. Growth and immunity of broiler chicks as affected by dietary arginine. Poultry Science 2001;80:1535-1542

Ma $X Y$, Lin $Y C$, Jiang ZY, Zheng $C T$, Zhou GL, Yu DQ. Dietary arginine supplementation enhances antioxidative capacity and improves meat quality of finishing pigs. Amino Acids 2010;38:95-102.

Munir K, Muneer MA, Masaoud E, Tiwari A, Mahmud A, Chaudhry RM, et al. Dietary arginine stimulates humoral and cell-mediated immunity in chickens vaccinated and challenged against hydropericardium syndrome virus. Poultry Science 2009;88:1629-1638.

Murakami AE, Fernandes JIM, Hernandes L, Santos TC. Effects of starter diet supplementation with arginine on broiler production performance and on small intestine morphometry. Pesquisa Veterinária Brasileira 2012:32:259-266

Saez G, Davall S, Gentes G, Hocquette JF, Jourdan T, Degrace P, et al. Gene expression and protein content in relation to intramuscular fat content in Muscovy and Pekin ducks. Poultry Science 2009;88:2382-2391.

SAS. SAS/STAT user's guide. Version 9.2. Cary: SAS Institute; 2008. 
Pirsaraei ZA, Rahimi A, Deldar H,

Sayyadi AJ, Ebrahimi M, Shahneh AZ,

Shivazad M, Tebianian M
Effect of Feedingarginine on the Growth

Performance, Carcass Traits, Relative Expression of Lipogenic Genes, and Blood Parametersof Arian Broilers
Tan B, Yin $Y$, Liu Z, Li $X, X u ~ H$, Kong $X$, et al. Dietary L-arginine supplementation increases muscle gain and reduces body fat mass in growing-finishing pigs. Amino Acids 2009;37:169-175.

Tan B, Yin Y, Liu Z, Tang W, Xu H, Kong $X$, et al. Dietary L-arginine supplementation differentially regulates expression of lipid-metabolic genes in porcine adipose tissue and skeletal muscle. Journal of Nutritional Biochemistry 2011;22:441-445.
Wu LY, Fang YJ, Guo XY. Dietary L-arginine supplementation beneficially regulates body fat deposition of meat-type ducks. British Poultry Science 2011;52:221-226.

Zechner R. The tissue-specific expression of lipoprotein lipase:implications for energy and lipoprotein metabolism. Current Opinion in Lipidolology 1997;8:77-88. 